\title{
Thermally tolerant symbionts may explain Caribbean octocoral resilience to heat stress
}

\author{
Jessie Pelosi ${ }^{1,5} \cdot$ Katherine M. Eaton ${ }^{1,6}$ - Samantha Mychajliw ${ }^{2}$ Casey P. terHorst $^{3}$. \\ Mary Alice Coffroth ${ }^{4}$ (B)
}

Received: 21 October 2020/Accepted: 12 May 2021/Published online: 29 May 2021

(C) The Author(s) 2021

\begin{abstract}
Coral reef ecosystems are under threat from the frequent and severe impacts of anthropogenic climate change, particularly rising sea surface temperatures. The effects of thermal stress may be ameliorated by adaptation and/or acclimation of the host, symbiont, or holobiont (host + symbiont) to increased temperatures. We examined the role of the symbiont in promoting thermal tolerance of the holobiont, using Antillogorgia bipinnata (octocoral host) and Breviolum antillogorgium (symbiont) as a model system. We identified five distinct genotypes of B. antillogorgium from symbiont populations isolated from Antillogorgia colonies in the Florida Keys. Three symbiont genotypes were cultured and maintained at $26^{\circ} \mathrm{C}$ (ambient
\end{abstract}

Jessie Pelosi and Katherine M. Eaton contributed equally to this work.

Topic editor Simon Davy

Supplementary Information The online version contains supplementary material available at https://doi.org/10.1007/s00338021-02116-8.

Mary Alice Coffroth

coffroth@buffalo.edu

1 Department of Biological Sciences, University at Buffalo, Buffalo, NY 14260, USA

2 Department of Environment and Sustainability, University at Buffalo, Buffalo, NY 14260, USA

3 Department of Biology, California State University, Northridge, Northridge, CA 91330, USA

4 Department of Geology, University at Buffalo, Buffalo, NY 14260, USA

5 Department of Biology, University of Florida, Gainesville, FL 32608, USA

6 Department of Biological Sciences, Auburn University, Auburn, AL 36849, USA historical temperature), and two were cultured and maintained at $30^{\circ} \mathrm{C}$ (elevated historical temperature) for $2 \mathrm{yrs}$. We analyzed the growth rate and carrying capacity of each symbiont genotype at both ambient and elevated temperatures in culture (in vitro). All genotypes grew well at both temperatures, indicating that thermal tolerance exists among these $B$. antillogorgium cultures. However, a history of long-term growth at $30{ }^{\circ} \mathrm{C}$ did not yield better performance for $B$. antillogorgium at $30^{\circ} \mathrm{C}$ (as compared to $26^{\circ} \mathrm{C}$ ), suggesting that prior culturing at the elevated temperature did not result in increased thermal tolerance. We then inoculated juvenile $A$. bipinnata polyps with each of the five symbiont genotypes and reared these polyps at both ambient and elevated temperatures (in hospite experiment). All genotypes established symbioses with polyps in both temperature treatments. Survivorship of polyps at $30{ }^{\circ} \mathrm{C}$ was significantly lower than survivorship at $26{ }^{\circ} \mathrm{C}$, but all treatments had surviving polyps at $56 \mathrm{~d}$ post-infection. Our results suggest broad thermal tolerance in $B$. antillogorgium, which may play a part in the increased resilience of Caribbean octocorals during heat stress events.

Keywords Symbiosis - Symbiodiniaceae - Octocorals · Thermal tolerance

\section{Introduction}

In recent years, anthropogenic climate change has severely impacted coral reefs, which comprise some of the most biodiverse and economically important ecosystems on Earth (Hoegh-Guldberg 2011; Hoegh-Guldberg et al. 2017). The success of coral reef ecosystems in oligotrophic tropical waters is due to corals' obligate endosymbioses 
with dinoflagellate algae in the family Symbiodiniaceae (Muscatine and Porter 1977). In this mutualistic relationship, the coral host relies on photosynthate produced by its intracellular symbionts to thrive (Muscatine and Cernichiari 1969; Muscatine and Porter 1977). In exchange for these metabolites, the symbiotic algae recover host nitrogenous waste. This relationship, which is vital to the survival of the reef ecosystem, is currently threatened by anthropogenic environmental changes.

Coral bleaching, or the loss of algal symbionts, occurs due to a variety of environmental stressors including changes in salinity, $\mathrm{pH}$, light intensity, and, most commonly, water temperature (Hoegh-Guldberg 1999). Most reef ecosystems now routinely encounter temperatures at or above their thermal maximum each year (Hoegh-Guldberg et al. 2007; Eakin et al. 2009), with bleaching events becoming more frequent and severe (Heron et al. 2016; van Hooidonk et al. 2016; Hughes et al. 2018; Oliver et al. 2018). As ocean temperatures continue to increase, it is essential to understand if and how corals and their symbionts can respond to the present threat.

In some cases, the holobiont (host + symbiont) responds to rising seawater temperatures via changes in the symbiont community within a single host, with the basic premise that hosts associating with more thermally tolerant symbionts will be more likely to survive bleaching events (i.e., shuffling and/or switching, sensu Baker 2003). Although most coral species host a single dominant symbiont type (Goulet 2006; LaJeunesse 2020), many hosts also harbor background or cryptic symbionts that are often undetected by traditional techniques (Mieog et al. 2007; Correa et al. 2009; Silverstein et al. 2012). During thermal stress, a more thermally tolerant background symbiont can become the dominant symbiont type, potentially conferring thermal tolerance to the holobiont (Berkelmans and van Oppen 2006; Jones et al. 2008; LaJeunesse et al. 2009; Keshavmurthy et al. 2012; Silverstein et al. 2015). In the aforementioned studies, the background symbionts often differed at the genus level and were typically replaced by the previously dominant symbiont type once the stress had subsided.

Thermally tolerant holobionts may arise through adaptation of symbiont populations, even in the absence of evolutionary changes in the host. Large population sizes, short generation times, and high mutation rates could greatly augment the standing genetic variation within symbiont populations (van Oppen et al. 2011). With greater standing variation, natural selection is more likely to produce populations with greater thermal tolerance (van Oppen et al. 2011; Torda et al. 2017; Quigley et al. 2018; Buerger et al. 2020). Numerous studies have established that more thermally tolerant symbionts can be selected from within a single symbiont genus or species (Howells et al. 2011; Chakravarti et al. 2017; Buerger et al. 2020). By sampling symbionts in the genus Cladocopium (ITS type $\mathrm{C} 1$ ) from reefs with different temperature regimes, Howells et al. (2011) showed that distinct symbiont genotypes had different thermal tolerances. Symbionts from the warmer reef displayed increased performance and survival at elevated temperatures as compared to those from the cooler environment. Furthermore, juvenile hosts inoculated with symbionts from the warmer reef performed better (grew faster, had less bleaching, and had lower mortality) than these inoculated with symbionts from the cooler region.

Chakravarti et al. (2017) and Buerger et al. (2020) presented evidence for selection within a species by examining the adaptive capabilities of the symbionts within a monoclonal culture of Cladocopium goreaui. Symbionts selected for thermal tolerance (i.e., those maintained at $31{ }^{\circ} \mathrm{C}$ for 2.5 to 4 yrs) performed better at $31{ }^{\circ} \mathrm{C}$ than the original monoclonal culture that had not undergone this selection treatment. Juvenile polyps infected with symbiont cells from the elevated temperature grew at $27{ }^{\circ} \mathrm{C}$ and $31{ }^{\circ} \mathrm{C}$, while polyps infected with the original culture showed negative growth at $31{ }^{\circ} \mathrm{C}$. Infection with some strains of thermally selected cells, however, did not reduce the rate or severity of bleaching compared to those infected with the original culture (Buerger et al. 2020). These studies establish that selection for thermal tolerance can occur over ecologically relevant time scales within at least some symbiont populations. Given sufficient standing genetic variation, this is likely the case for other species within Symbiodiniaceae and requires further inquiry (Chakravarti et al. 2017).

By starting with a single monoclonal culture, all genetic variation in the symbionts used by Chakravarti et al. (2017) and Buerger et al. (2020) likely arose from de novo mutation. However, intraspecific markers have revealed numerous instances where host colonies harbor multiple genotypes within a symbiont species (Santos et al. 2003; Pettay and LaJeunesse 2007; Howells et al. 2009; Kirk et al. 2009), suggesting the possibility for selection on preexisting genetic variation within in hospite populations, resulting from both mutation and recombination (Baums et al. 2014; Chi et al. 2014; Wilkinson et al. 2015; Thornhill et al. 2017). Indeed, many studies have found variation in thermal tolerance within a single symbiont species (Parkinson and Baums 2014; Karim et al. 2015; Díaz-Almeyda et al. 2017; Grégoire et al. 2017; Bayliss et al. 2019). For example, Bayliss et al. (2019) identified genetic and trait variation within and among Breviolum species isolated from the octocoral Antillogorgia bipinnata.

Here, we ask if there are thermally tolerant genotypes present in a symbiont species within a single host colony. We utilized the octocoral A. bipinnata and its host- 
specialist endosymbiotic algae, Breviolum antillogorgium, as a model to study the role of symbiont genetic variation in the thermal response of the holobiont. We first attempted to select for thermally tolerant symbionts from in hospite populations to capitalize on pre-existing genetic variation. We then examined symbiont growth at two temperatures with an in vitro experiment using these cultured isolates of B. antillogorgium. Subsequently, we examined whether thermal tolerance in the symbiont could be conferred to the host using an in hospite experiment. Thermally tolerant symbionts within a population contained in a single host colony expand the potential for the holobiont to improve its thermal tolerance, potentially slowing the loss of these invaluable ecosystems.

\section{Methods}

\section{Symbiont isolation}

Although culturing Symbiodiniaceae is highly selective and rarely recovers the symbionts dominant within the host (Santos et al. 2001; LaJeunesse 2002), Breviolum antillogorgium (ITS2-type B1) has been successfully cultured and associates specifically with octocorals in the genus Antillogorgia (Santos et al. 2004; Parkinson et al. 2015). Symbiont cells were isolated from sixteen adult Antillogorgia colonies collected from 11-18 m depth at sites in Elbow and Pickles Reefs, Florida Keys in September 2016 (Table 1). A sample of each host colony was preserved in 95\% ethanol for comparison of dominant host symbionts with those isolated. An approximately $2 \mathrm{~cm}$ piece was sampled from each colony and homogenized in $2 \mathrm{~mL}$ of filtered seawater (FSW). Each homogenate was passed through a series of mesh filters $(250,120,70$ and $20 \mu \mathrm{m})$, followed by several $1 \mathrm{~mL} 0.22 \mu \mathrm{m}$ FSW rinses for a final volume of 3-6 mL. Homogenates were spun at $800 \mathrm{rpm}$ for $5 \mathrm{~min}$. Supernatants were decanted, and the pellets were resuspended in $10 \mathrm{~mL}$ of FSW. This was repeated three additional times, followed by resuspending each pellet in $1 \mathrm{~mL}$ of f/2 media (Guillard and Ryther 1962). For each colony, $50 \mu \mathrm{L}$ of the resultant cell suspension was added to six flasks containing $30 \mathrm{~mL}$ of $\mathrm{f} / 2$ media. Three flasks of the symbionts from each colony were maintained at $26{ }^{\circ} \mathrm{C}$, mimicking typical thermal conditions, and three were immediately placed at $30^{\circ} \mathrm{C}$ in an attempt to select for more thermally tolerant genotypes that can survive at an elevated temperature. An elevated temperature of $30^{\circ} \mathrm{C}$ was chosen based on the historical thermal regime of the collection site during November/December (mean maximum over $15 \mathrm{yr}=27.2^{\circ} \mathrm{C}$ at $3 \mathrm{~m}$ on Elbow Reef, Williams and Miller 2015; Online Resource 1), when newly settled A. bipinnata polyps acquire symbionts. Initial growth, observed as a small dot at bottom of the flask, was immediately transferred into a new flask with fresh media. This was repeated each time new growth was observed in any flask over the first month, resulting in 131 cultures. All cultures were transferred to fresh media monthly.

\section{Genotype identification}

After 2 yrs (approximately 256-284 asexual generations, see in vitro experiment), total symbiont genomic DNA from 106 cultures and the host source colonies were extracted using the $2 \times$ CTAB method (Coffroth et al. 1992) and diluted to 5-10 $\mathrm{ng} \mu \mathrm{L}^{-1}$, and the flanking region of the B7Sym15 microsatellite (Pettay and LaJeunesse 2007) was sequenced (TACGEN, Richmond, California, the USA). Sequences were compared to available sequences on NCBI using BLASTn for symbiont species-level identification.
Table 1 Five genotypes of Breviolum antillogorgium selected for in vitro and in hospite experiments

\begin{tabular}{lllllll}
\hline Genotype & Selection temp & Source colony & Reef & Depth $(\mathrm{m})$ & Location & Accession no \\
\hline $\mathbf{G - 1}$ & $26{ }^{\circ} \mathrm{C}$ & 7 & Elbow & 18 & N 25 07.925 & MW207288 \\
& & & & & W 80 15.717 & \\
$\mathbf{G - 2}$ & $26{ }^{\circ} \mathrm{C}$ & 5 & Elbow & 11 & N 25 07.956 & MW207289 \\
& & & & W 80 15.810 & \\
$\mathbf{G - 3}$ & $26{ }^{\circ} \mathrm{C}$ & 8 & Elbow & 18 & N 25 07.925 & MW207287 \\
& & & & & W 80 15.717 & \\
$G-4$ & $30{ }^{\circ} \mathrm{C}$ & 8 & Elbow & 18 & N 25 07.925 & MW207285 \\
& & & & & W 80 15.717 & \\
$G-5$ & $30{ }^{\circ} \mathrm{C}$ & 8 & Elbow & 18 & N 25 07.925 & MW207286 \\
& & & & & W 80 15.717 & \\
\hline
\end{tabular}

Emphasis refers to selection temperature, bold indicating cultures maintained at $26{ }^{\circ} \mathrm{C}$ and italic indicating cultures maintained at $30{ }^{\circ} \mathrm{C} 2$ yrs prior to the start of the experiment. Cultures were isolated from Antillogorgia colonies collected at Elbow Reef, Florida Keys 
Cultures identified as $B$. antillogorgium $(n=24)$ and samples from the source colonies of these cultures were amplified with five microsatellite loci following published protocols: CA 6.38 (Santos et al. 2003), GV_1C (Andras et al. 2009), B7Sym8, B7Sym34, and B7Sym36 (Pettay and LaJeunesse 2007). Amplicons were labeled with fluorescently tagged primers and visualized on a $6.5 \%$ polyacrylamide gel with the LI-COR NEN Global IR2 DNA Sequencer (LI-COR Biotechnology Division) following Santos et al. (2003). Allele sizes were scored by eye relative to size standards between 50 and $350 \mathrm{bp}$. Based on the microsatellite results, $21 \mathrm{~B}$. antillogorgium cultures were unialgal and contained one of five genotypes. Ultimately, this resulted in the occurrence of three distinct genotypes (referred to here as G1, G2, and G3) from one or more of the cultures reared at $26{ }^{\circ} \mathrm{C}$ and two genotypes (referred to here as G4 and G5) from one or more of the cultures reared at $30{ }^{\circ} \mathrm{C}$ (see "Results"). One of each of these five genotypes was used in the experiments outlined below (Table 1).

\section{In vitro growth experiments}

Six replicates of each of the five cultures identified above were started by inoculating $18 \mathrm{~mL}$ of $\mathrm{f} / 2$ media with 10,000 cells $\mathrm{mL}^{-1}$. Three of the replicates for each culture were subsequently grown at $25.53 \pm 0.89{ }^{\circ} \mathrm{C}$ (mean \pm $\mathrm{SD}$; referred to as " $26{ }^{\circ} \mathrm{C}$ "), and three were grown at $29.84 \pm 0.48{ }^{\circ} \mathrm{C}$ (mean $\pm \mathrm{SD}$; referred to as “30 ${ }^{\circ} \mathrm{C}$ ”) on a 12:12 h light:dark cycle (Fig. 1). Light levels were maintained at $120.58 \pm 11.14 \mu$ mols $\mathrm{m}^{-2} \mathrm{~s}^{-1}$ (mean \pm SD) (Philips Energy Advantage T5 HO $49 \mathrm{~W}$ ) and $103.79 \pm 37.3 \mu$ mols $\mathrm{m}^{-2} \mathrm{~s}^{-1}$ (mean $\pm \mathrm{SD}$ ) (Philips $\mathrm{T} 5$ HO $24 \mathrm{~W} / 840$ ) for the $26{ }^{\circ} \mathrm{C}$ and $30{ }^{\circ} \mathrm{C}$ incubators, respectively (Welch's Two Sample t-test, $\mathrm{p}=0.13$ ). Cell densities were measured using six replicate hemocytometer cell counts every $3 \mathrm{~d}$. Experiments were continued until cell density peaked and exhibited a consistent decline in abundance. We used the 'growthrates' package ver. 0.8.1 (Petzoldt 2019) in R ver. 4.0.2 (R Core Team 2020) to fit logistic growth curves to the cell counts over time, up to the maximum cell count for each culture. We extracted values of $r$ and $K$ from the 'growthrates' package and used these as estimates of maximum population growth rate and carrying capacity, respectively. Doubling time (2.57 to $2.86 \mathrm{~d}$ ) and number of generations (approximately 256-284 generations) were calculated following Chakravarti et al. (2017), using cell density at the end of $30 \mathrm{~d}$ (Online Resource 2). Samples of each replicate were then preserved in $95 \%$ ethanol, from which DNA was extracted and amplified following the methods detailed above to verify symbiont genotype at the end of the experiment.

\section{In hospite polyp experiments}

Branches from adult colonies of $A$. bipinnata, a gonochoric surface brooder (Kahng et al. 2011), were collected from Tennessee Reef, Florida Keys in November 2018 (N 24 $45.150^{\prime} \mathrm{W} 81^{\circ} 45.275^{\prime}$ ). These branches were transported to flow-through seawater tanks at Keys Marine Laboratory, where they were monitored daily for release of embryos. Aposymbiotic brooded larvae were collected from the colony surface on $16,17,22,23,25$, and 26 November, washed three times in $0.22 \mu \mathrm{m}$ filtered instant ocean (FIO) and transferred to Buffalo, NY. Following transport, larvae (4-14 d old) were again washed in FIO to remove environmental contaminants and groups of 25 larvae were transferred to pre-conditioned polypropylene containers (volume $=$ approximately $115 \mathrm{~mL}$ ) with $50 \mathrm{~mL}$ of FIO. For pre-conditioning, the bottom and sides of each container were roughened with sandpaper and then soaked for four weeks in $1.2 \mu \mathrm{m}$ filtered seawater (FSW) to establish a biofilm. Once larvae were added, water in the containers (FIO) was changed daily for one week, then every other day until larvae settled and metamorphosed into polyps (approximately 4 weeks). Containers of newly settled polyps (approximately 1-2 weeks post-settlement) were then divided into five treatments (G1 through G5, Online Resource 3), and each treatment was inoculated with 1000 cells $\mathrm{mL}^{-1}$ of one of the five genotypes of $B$. antillogorgium utilized in the in vitro experiments (Table 1, Fig. 1). For each genotype, 9-10 containers were placed at $26{ }^{\circ} \mathrm{C}\left(25.51 \pm 1.10{ }^{\circ} \mathrm{C}\right.$; mean $\left.\pm \mathrm{SD}\right)$ and $6-8$ at $30{ }^{\circ} \mathrm{C}$ $\left(29.79 \pm 0.28^{\circ} \mathrm{C}\right.$; mean $\left.\pm \mathrm{SD}\right)$ and maintained in a 12:12 h light:dark cycle. Initial inoculations occurred twice over a period of one week. Polyp locations in the containers were mapped, and survival for each individual polyp was recorded every 3-4 d with water changes. Visual infection, indicated by a light brown coloration in the polyp, was limited within the first month following initial introduction of symbionts. To increase the likelihood of the establishment of the symbiosis, inoculations were repeated with each water change during the second month and combined with feeding with Reefs-Roids (Polyplab, Quebec, Canada) (2 mL of Reef-Roids solution at a concentration of $1 \mathrm{mg} \mathrm{mL}^{-1}$ FIO) to induce symbiont uptake. Inoculations continued throughout the second month, and establishment of the symbiosis through visual observation was recorded throughout the experiment. An unidentified green alga, first observed in three containers on Day 42, but subsequently found in several additional containers on Days 56-59, led to extensive polyp mortality over time. After 69 d, all surviving polyps were collected, symbiont cell density was determined (as detailed above), and tissue was preserved in $95 \%$ ethanol. Symbiont DNA was extracted from preserved tissue, and symbiont genotype 

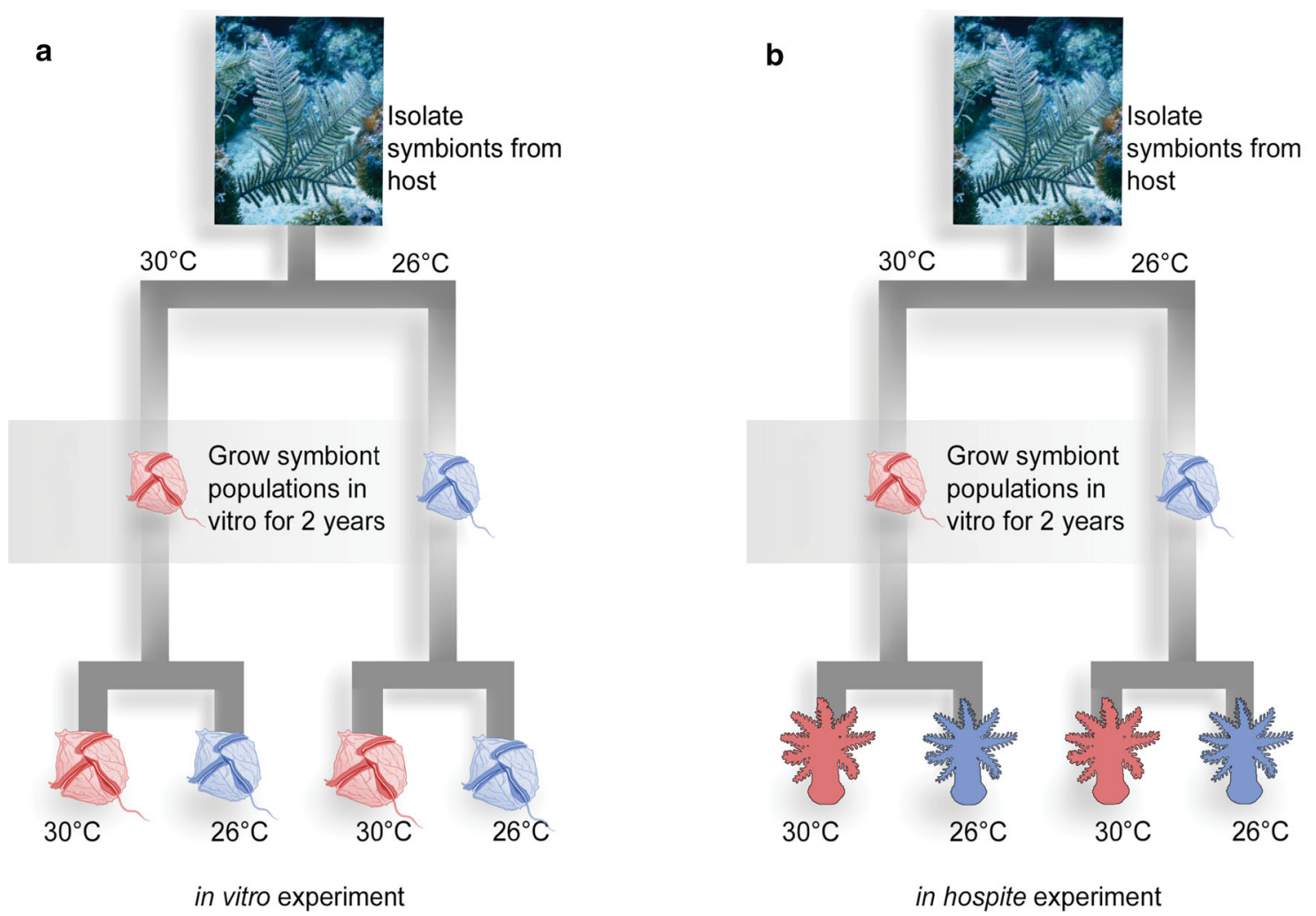

Fig. 1 Experimental design for $\mathbf{a}$ in vitro growth experiment and $\mathbf{b}$ in hospite experiment. Figure colors refer to historical temperature treatment (blue, maintained at $26{ }^{\circ} \mathrm{C}$; red, maintained at $30{ }^{\circ} \mathrm{C}$ ), with tip figures colored based on experimental treatment (not historical temperature)

was verified using the five microsatellite loci described above.

\section{Statistical analyses}

We analyzed the effects of temperature treatment and genotype on in vitro symbiont maximum population growth rates and carrying capacity using separate two-way ANOVAs for each dependent variable ( $r$ and $K$ ), including the interaction term between these factors (temperature and genotype). Data were log-transformed to meet assumptions of homoscedasticity for the in vitro analyses. For the in hospite experiment, we quantified polyp survivorship as the proportion of surviving polyps after 31 and $52 \mathrm{~d}$ post-initial inoculation. These time points were prior to the observation of widespread contamination by the unidentified green alga, to avoid the possibility that this affected survivorship. Containers in which the contaminating algae was observed prior to Day $52(n=5)$ were excluded from survivorship analyses beginning at the first observation of contamination. We analyzed survivorship over the first $31 \mathrm{~d}$ and then from Day 32 to Day 52 as described above; with survivorship for Days 1-31 arcsine transformed to meet assumptions of normality. (Survivorship data for Days 32-52 were not transformed as the raw data fit the assumptions of the model without transformation.) We analyzed temperature and genotype effects on visually observed infection at Days 31 and 52 as well as on symbiont cell densities at the end of the experiment (Day 69) as above. Symbiont cell densities were square-root transformed to meet assumptions of the model. Assumptions of normality and homogeneity were checked using residuals and Q-Q probability plots. All post hoc pairwise comparisons were carried out using Tukey's HSD (honest significance test) (Tukey 1949). In vitro statistical analyses were conducted in $\mathrm{R}$ ver. 4.0.2 and in hospite analyses in $\mathrm{R}$ ver. 3.6.1 (R Core Team 2020). $\mathrm{R}$ scripts are available at www. github.com/jessiepelosi/symbiont_tolerance, and raw data are available at https://www.bco-dmo.org/award/658940.

\section{Results}

\section{Sequencing and genotyping}

Following 2 yrs of growth at either $26{ }^{\circ} \mathrm{C}$ or $30{ }^{\circ} \mathrm{C}$, there were 131 viable cultures. The majority of cultures (106 of 131) either could not be classified or aligned most closely with B. minutum, a species commonly recovered from a range of species where it is undetected by normal 
techniques (LaJeunesse et al. 2012; Parkinson et al. 2015). Twenty-four of the cultures were identified as $B$. antillogorgium based on a comparison of B7Sym 15 microsatellite flanking region sequences to available sequences on NCBI. Three of these cultures contained multiple genotypes. Each of the remaining $21 \mathrm{~B}$. antillogorgium cultures was unialgal and contained one of five genotypes. Ten $B$. antillogorgium cultures reared at $26{ }^{\circ} \mathrm{C}$ were either genotype $\mathrm{G} 1, \mathrm{G} 2$, or $\mathrm{G} 3$, while $11 \mathrm{~B}$. antillogorgium cultures reared at $30^{\circ} \mathrm{C}$ were genotype G4 or G5. These five genotypes were used in the in vitro and in hospite experiments. Based on microsatellite genotyping, one of the five genotypes (G3) was the same as the dominant genotype in the source colony; the other four genotypes represented background symbionts as is common in culturing from host tissue (Santos et al. 2001; LaJeunesse 2002; LaJeunesse et al. 2012; Parkinson et al. 2015).

\section{In vitro growth experiments}

Cultures reached their maximum cell density in 28-40 days and maintained this density for at least several days afterward (Fig. 2a, Online Resource 4). The effect of temperature on maximum population growth rate was dependent on the symbiont genotype (Temperature $\times$ Genotype: $\left.F_{4,20}=30.20, p<0.001\right)$. At $30^{\circ} \mathrm{C}$, the mean growth rate for two of the five genotypes (G1 and G2) was significantly lower than that at $26{ }^{\circ} \mathrm{C}$; there was no significant effect of temperature for the remaining three genotypes (Fig. 2a, b). The effect of temperature on carrying capacity was also dependent on the symbiont genotype (Temperature $\times$ Genotype: $F_{4,20}=17.90, p<0.001$ ). One genotype (G3) showed a decrease in carrying capacity at the elevated temperature, but the remaining genotypes showed non-significant responses to temperature (Fig. 2c). The time for populations to reach their peak abundance was also dependent on the interaction between temperature and symbiont genotype (Temperature $\times$ Genotype: $F_{4,20}=6.57, p=0.002$ ).

\section{In hospite polyp experiments}

For the first $31 \mathrm{~d}$, we did not find a significant effect of genotype $\quad\left(F_{4,73}=1.84, \quad p=0.130\right), \quad$ temperature $\left(F_{1,73}=0.03, p=0.861\right)$, nor Temperature $\times$ Genotype $\left(F_{4,73}=0.83, p=0.508\right)$ on the proportion of visually infected polyps (Fig. 3a). Similarly, between 32 and 52 d, we did not find a significant effect of genotype $\left(F_{4,56}=0.66, \quad p=0.623\right), \quad$ temperature $\quad\left(F_{1,56}=3.77\right.$, $p=0.057)$, nor Temperature $\times$ Genotype $\left(F_{4,56}=1.22\right.$, $p=0.312$ ) on the proportion of visually infected polyps (Fig. 3b). We found a significant interaction between the effects of temperature and genotype on the symbiont cell densities in polyps at the end of the experiment, when the vast majority of polyps (range $66-100 \%$ of polyps per treatment) were infected (69 d post-first inoculation, $F_{4,264}=6.34, p<0.001$ ). Average symbiont densities in polyps varied between genotypes, depending on temperature at Day 69 (termination of the experiment, Fig. 3c). Polyp survivorship at the end of the first 31 days was not significantly affected by symbiont genotype $\left(F_{4,74}=0.81\right.$, $p=0.522)$, nor by treatment temperature $\left(F_{1,74}=3.05\right.$, $p=0.085)$, and there was not a significant interaction term $\left(F_{4,74}=0.76, p=0.574\right)$ (Fig. 4a, b). Polyp survivorship at the end of $52 \mathrm{~d}$ decreased dramatically in both temperature treatments (Fig. $4 \mathrm{a}, \mathrm{c}$ ), with those polyps at $30{ }^{\circ} \mathrm{C}$ having significantly lower survivorship than these reared at $26^{\circ} \mathrm{C}$ $\left(F_{1,68}=15.64, p<0.001\right)$. There was not a significant effect of genotype $\left(F_{4,68}=2.11, p=0.089\right)$ nor the interaction between temperature and genotype on survival for the second period (Temperature $\times$ Genotype, $F_{4,68}=0.13$, $p=0.970$ ). Including the five containers removed after Day 42 (due to algal contamination) did not change the results. Although survivorship results are only reported prior to the appearance of an unidentified green alga, all treatments were maintained for $69 \mathrm{~d}$. At that time, all treatments except $\mathrm{G} 4$ at $30{ }^{\circ} \mathrm{C}$ had surviving polyps (range 2-70 polyps per treatment).

\section{Discussion}

Cultured symbionts isolated from standing genetic variation within host colonies revealed the presence of multiple genotypes capable of growth at $30^{\circ} \mathrm{C}$, with three of the five unique genotypes used here isolated from a single host colony (Table 1). However, there was no clear evidence of selection for increased thermal tolerance in cultures reared at $30{ }^{\circ} \mathrm{C}$ for over 250 generations ( 2 yrs) compared to those reared at $26^{\circ} \mathrm{C}$ over this time (Figs. 2, 3, 4). Genotypic variability was clear as genotypes differed in their response to thermal stress (i.e., growth rate and carrying capacity, Fig. 2). Regardless of this variability, all tested genotypes showed growth at $30{ }^{\circ} \mathrm{C}$, suggesting that $\mathrm{Bre}$ violum antillogorgium, as a species, is thermally tolerant.

\section{In vitro growth experiments}

By isolating genotypes from standing genetic variation among in hospite populations that were able to sustain long-term growth at temperatures above the seasonal maximum, we established that thermally tolerant symbiont genotypes are present within the host. We maintained these cultures at $30{ }^{\circ} \mathrm{C}$ for 2 yrs to select for long-term growth at elevated temperatures, anticipating that these cultures would adapt and outperform other genotypes at elevated 


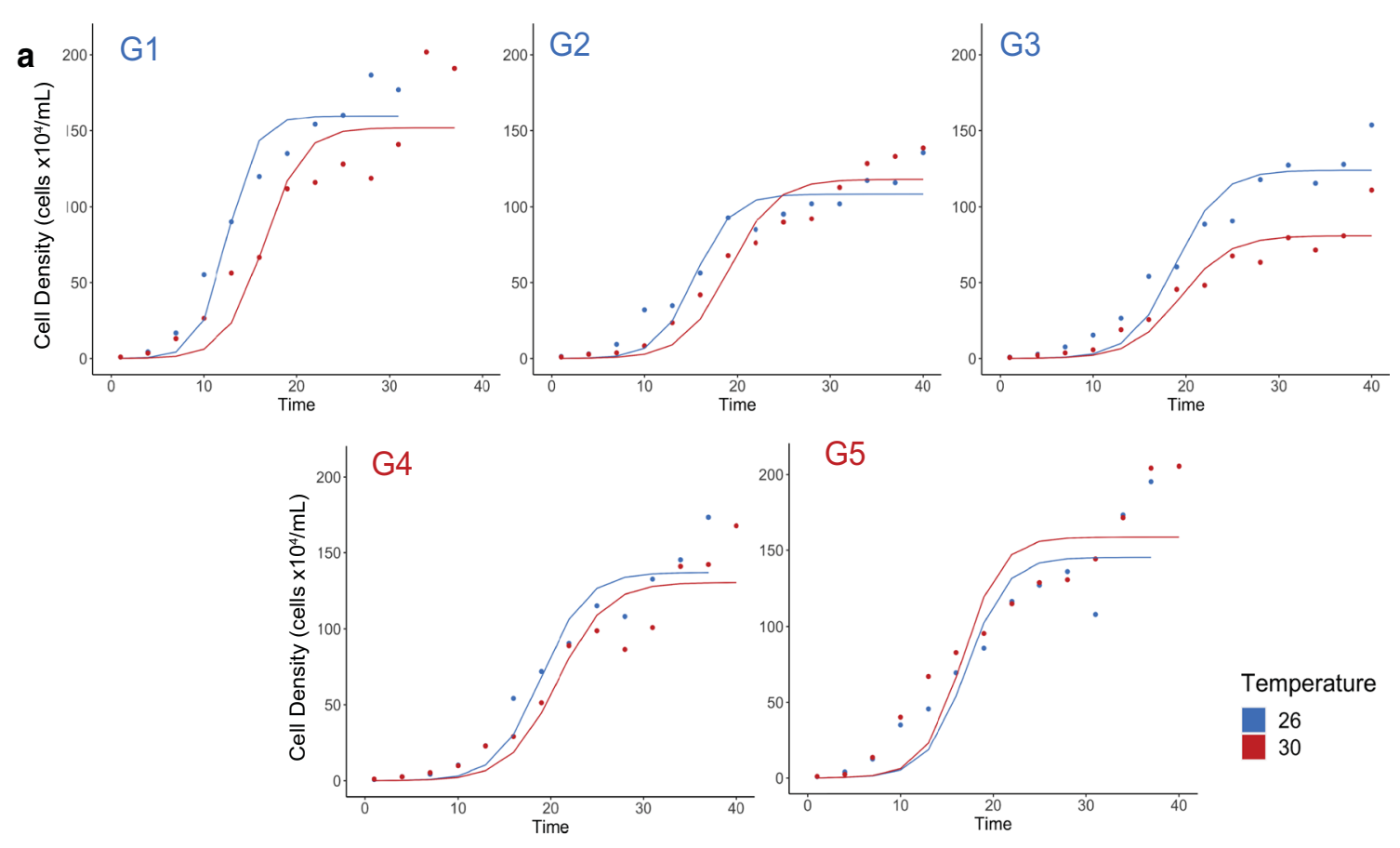

b

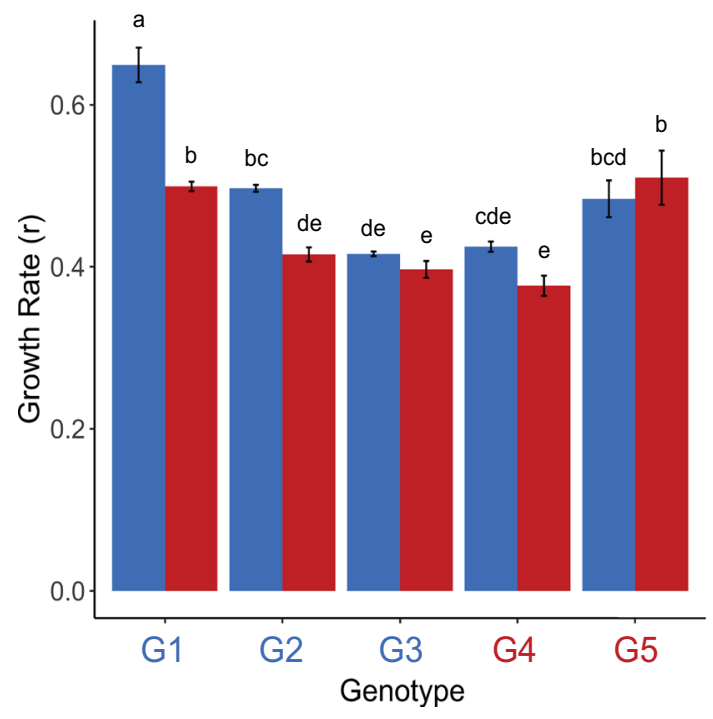

Fig. 2 a Mean logistic growth fits to in vitro cell densities of each genotype of Breviolum antillogorgium over time. Blue represents growth at $26{ }^{\circ} \mathrm{C}$ and red at $30{ }^{\circ} \mathrm{C}$. b Estimated mean $(+/-\mathrm{SE})$ maximum symbiont population growth rates $(r)$ and $\mathbf{c}$ estimated mean $(+/-\mathrm{SE})$ carrying capacities $(K)$. Colors for genotype names $(x-$

temperatures. Unlike previous studies that found evidence for increased thermal adaptation in Symbiodiniaceae after one to $2.5 \mathrm{yrs}$ of exposure to increased temperatures (Cladocopium-Chakravarti et al. 2017; Buerger et al. 2020; Fugacium, Gerakladium, Symbiodinium-Chakravarti and van Oppen 2018), a history of long-term growth at $30{ }^{\circ} \mathrm{C}$ did not yield better performance for $B$. antillogorgium at $30^{\circ} \mathrm{C}$ (as compared to $26^{\circ} \mathrm{C}$ ). Our results c

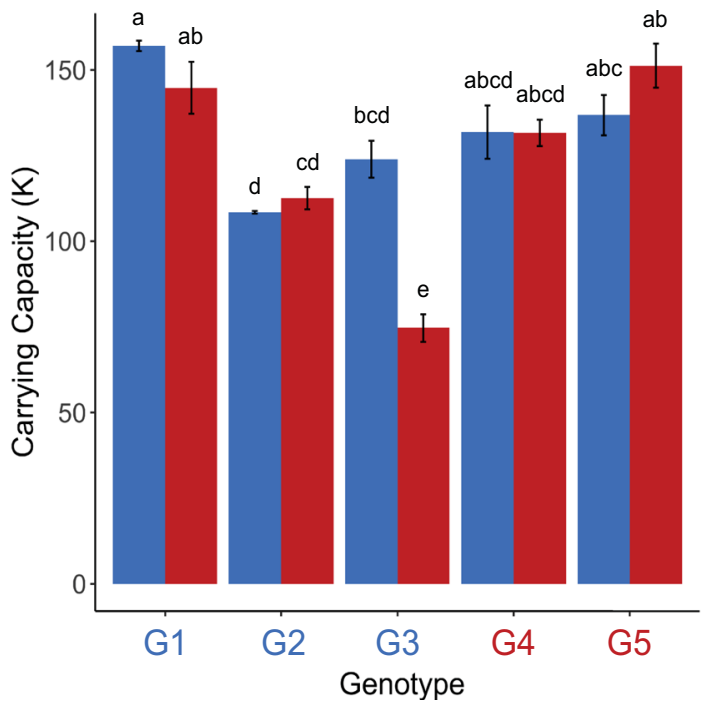

axis) refer to the historical temperature at which they were grown, blue indicating cultures maintained at $26^{\circ} \mathrm{C}$ and red indicating cultures maintained at $30{ }^{\circ} \mathrm{C} 2$ yrs prior to the start of the experiment. Letters above bars represent differences among groups based on Tukey post hoc tests

suggest that local adaptation to this temperature did not occur over this time. The ability of all cultures to survive and grow positively at $30{ }^{\circ} \mathrm{C}$ for several months, regardless of historical temperature, suggests that these genotypes of B. antillogorgium possess pre-existing, broad thermal tolerance, possibly due to plastic acclimatory responses.

Growth rate serves as a good proxy for fitness of symbiont populations. Carrying capacity may serve as a proxy 


\section{a Day 31}

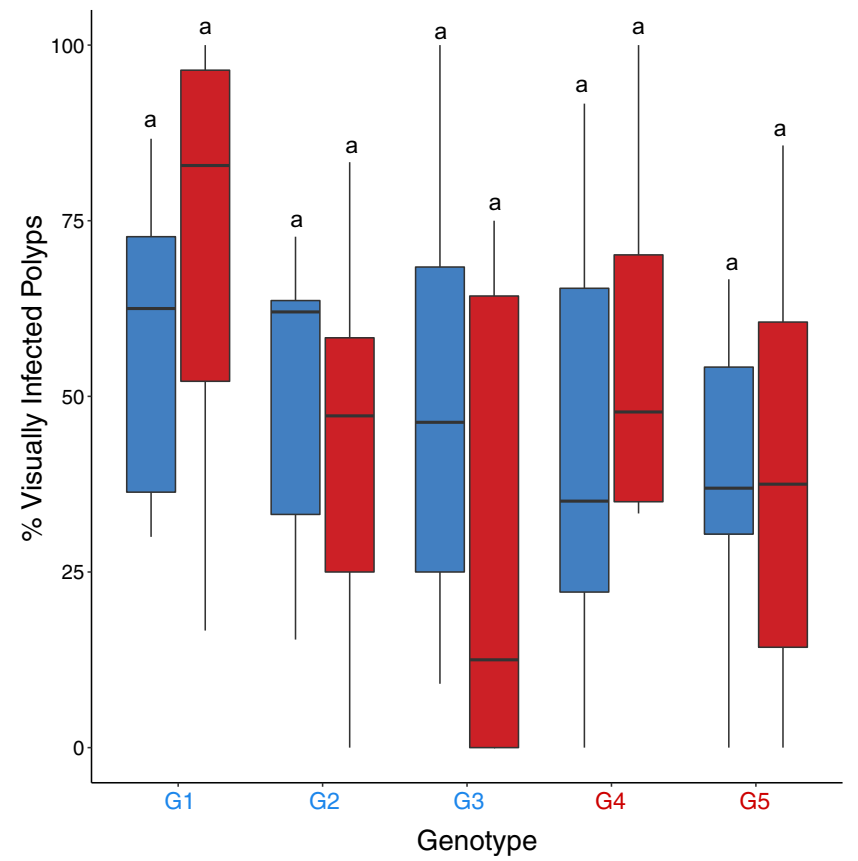

c Day 69 b Day 52

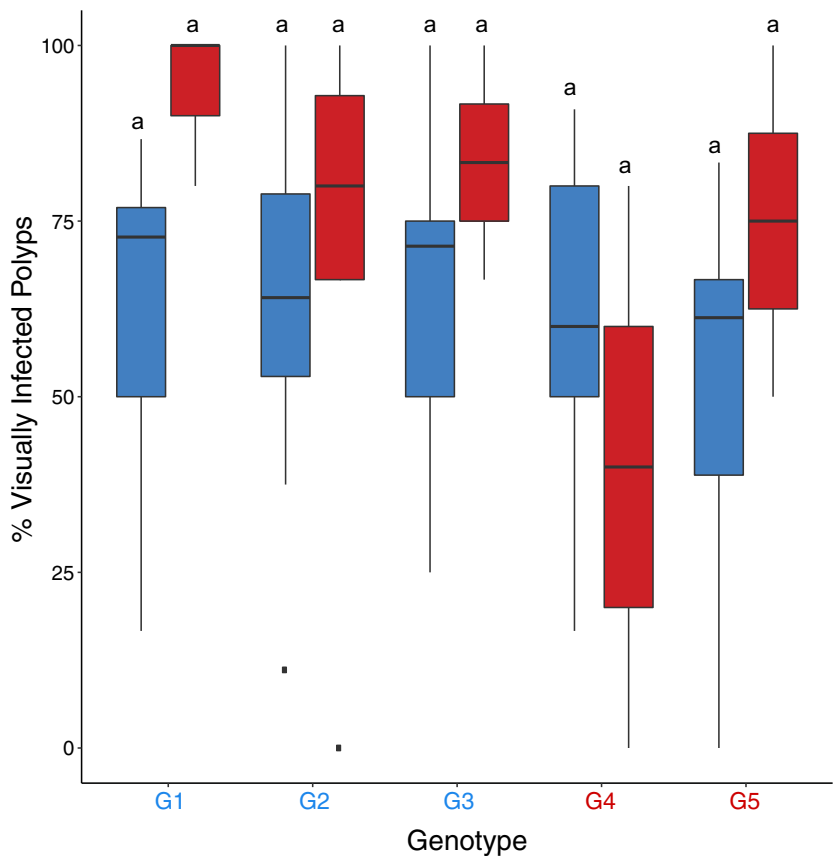

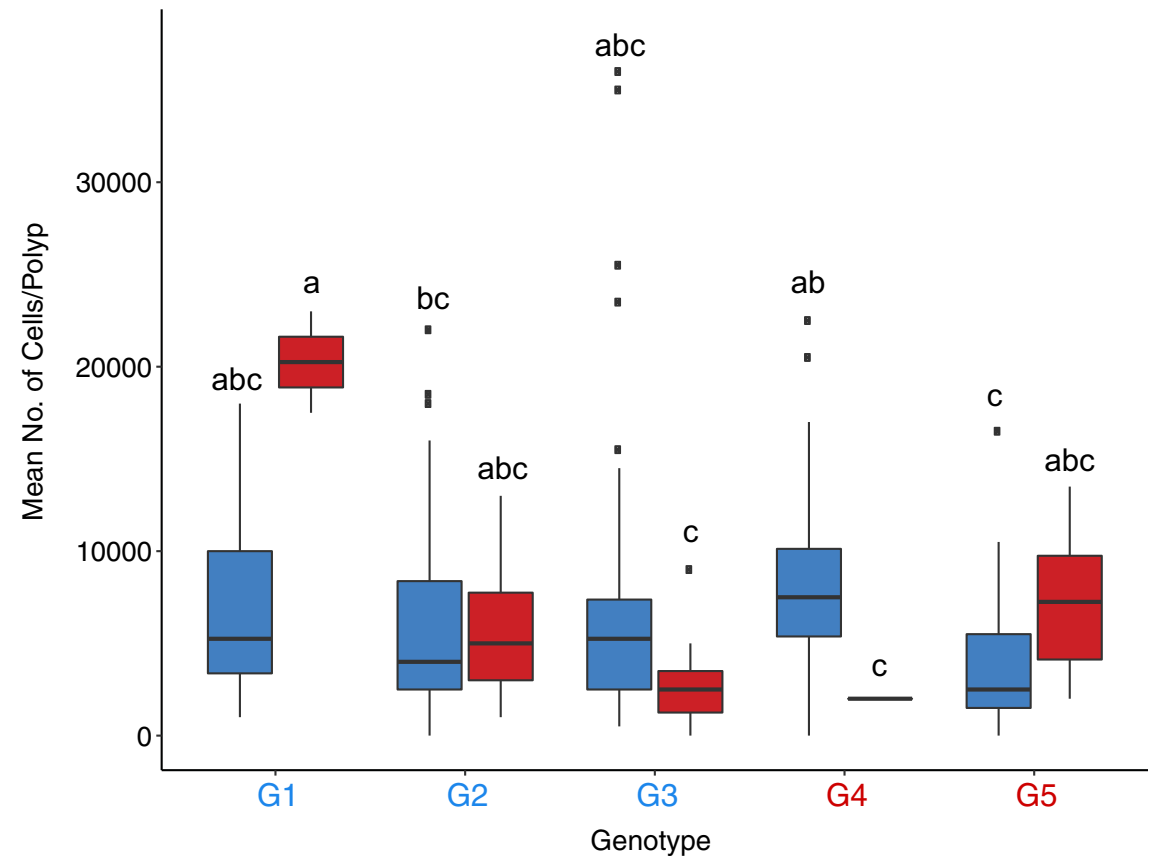

Fig. 3 Mean percent of visually infected polyps at the end of a Day 31 and b Day 52. c Symbiont cell densities within Antillogorgia bipinnata polyps inoculated with five symbiont genotypes at $26{ }^{\circ} \mathrm{C}$ and $30{ }^{\circ} \mathrm{C}$ at the end of the experiment (Day 69). Colors for genotype names (x-axis) refer to historical temperature, blue indicating cultures maintained at $26{ }^{\circ} \mathrm{C}$ and red indicating cultures maintained at $30{ }^{\circ} \mathrm{C}$

for efficiency of resource use because it suggests that more organisms can be sustained at the same level of resource. We found variation among genotypes in carrying capacity,

2 yrs prior to the start of the experiment. Color of boxes refers to experimental temperature (blue $-26{ }^{\circ} \mathrm{C}$, red $-30{ }^{\circ} \mathrm{C}$ ). Boxes represent interquartile range and whiskers the range of the data. Points indicate outliers. Letters above boxes represent differences among groups based on Tukey post hoc tests

but interestingly, also found variation in the response of carrying capacity to increased temperature. One genotype (G3) showed a significant decrease in carrying capacity at 
a

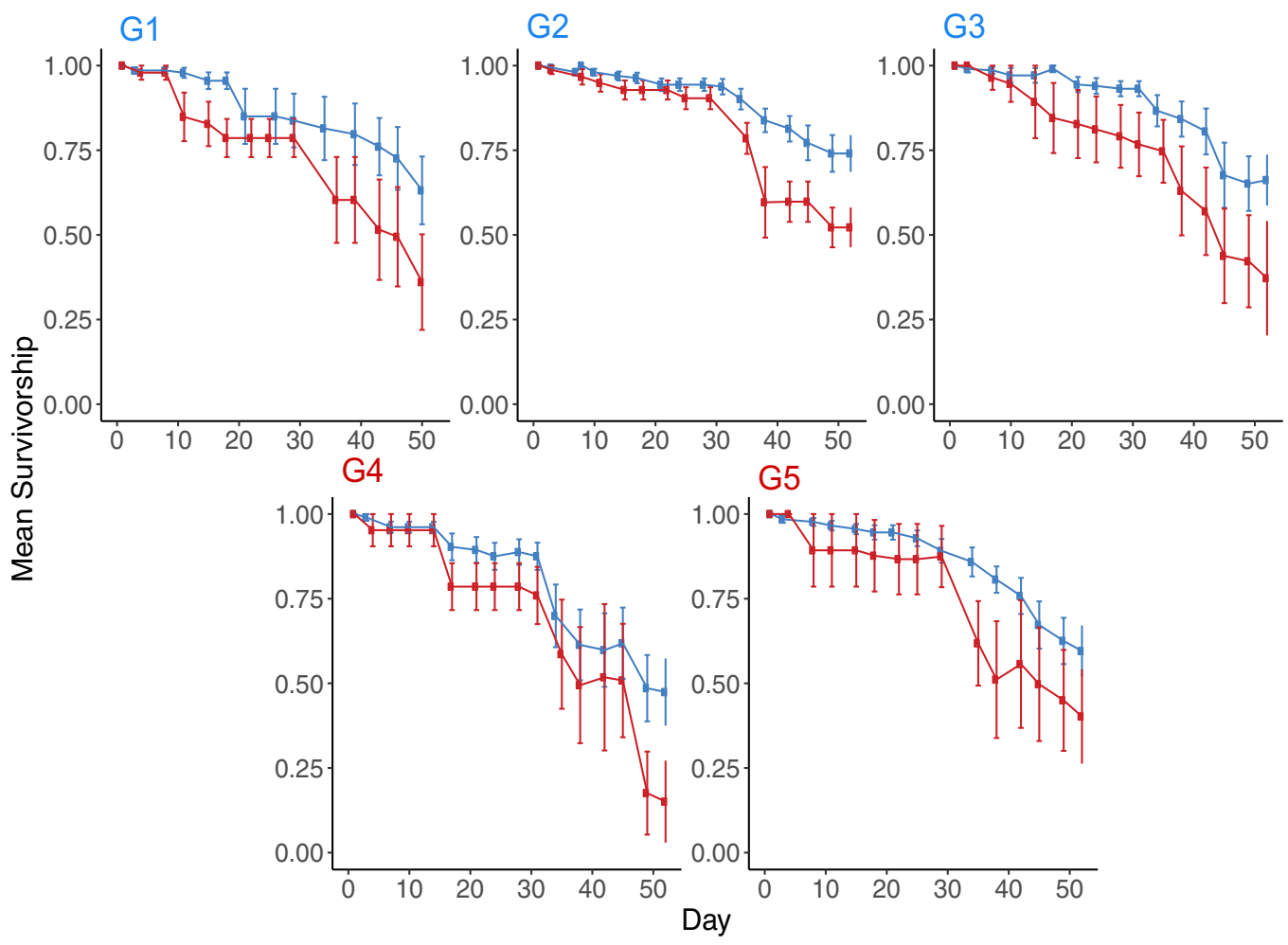

b Day 31

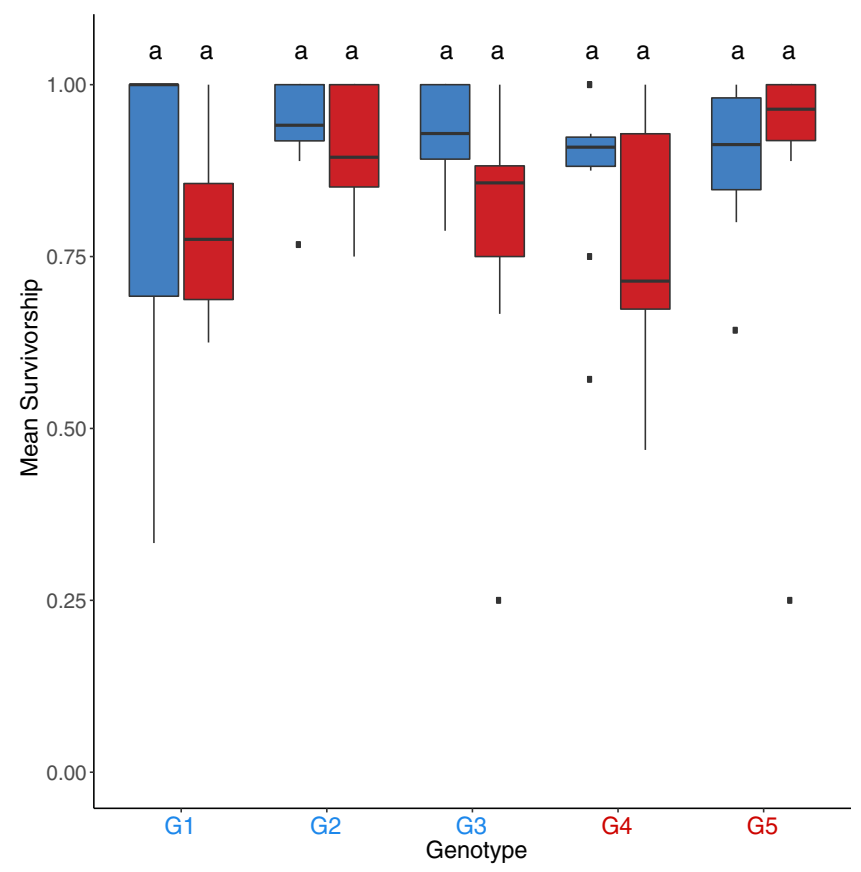

Fig. 4 a Mean polyp survivorship over time for A. bipinnata polyps inoculated with five symbiont genotypes at $26{ }^{\circ} \mathrm{C}$ and $30^{\circ} \mathrm{C}$. Error bars are \pm SE. Blue lines refer to treatments at $26{ }^{\circ} \mathrm{C}$, and red lines refer to treatments at $30{ }^{\circ} \mathrm{C}$. Differences in average survivorship at b Day 31 and c Day 52. Colors for genotype names ( $x$-axis) refer to historical temperature, blue indicating cultures maintained at $26^{\circ} \mathrm{C}$

\section{c Day 52}

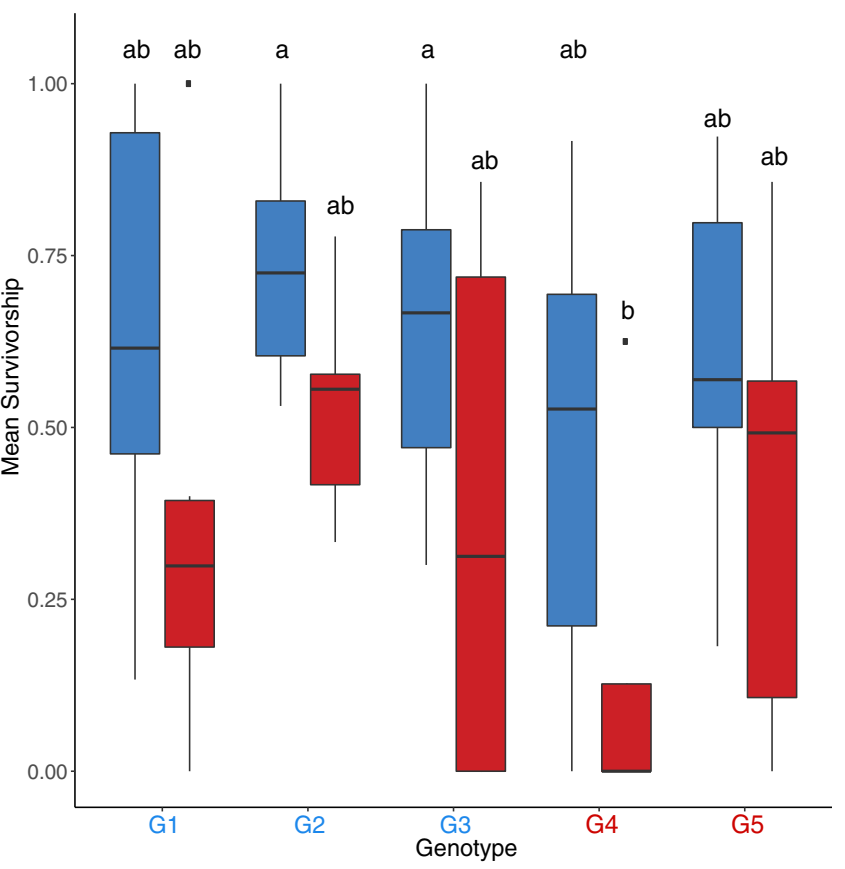

and red indicating cultures maintained at $30{ }^{\circ} \mathrm{C} 2$ yrs prior to the start of the experiment. Color of boxes refers to experimental temperature (blue $-26{ }^{\circ} \mathrm{C}$, red $-30{ }^{\circ} \mathrm{C}$ ). Boxes represent interquartile range and whiskers the range of the data. Points indicate outliers. Letters above boxes represent differences among groups based on Tukey post hoc tests 
higher temperature (Fig. 2c), but the remaining four genotypes showed non-significant responses to temperature.

Prior studies examining the potential for symbionts to adapt to elevated temperatures have focused on a single genotype (Chakravarti et al. 2017; Chakravarti and van Oppen 2018), but in the present study, we used several genotypes within the same species, selected from pre-existing genetic variation within in hospite populations. Variability in response to elevated temperatures observed among the genotypes used in our experiments highlights the potential role of intraspecific genetic variation in responding to thermal stress and further underscores the importance of examining both intrageneric and intraspecific variation in thermal responses. Other in vitro studies (Chakravarti et al. 2017; Chakravarti and van Oppen 2018; Buerger et al. 2020) have explored how dinoflagellate symbionts in other genera respond to temperatures higher $\left(31{ }^{\circ} \mathrm{C}-34^{\circ} \mathrm{C}\right)$ than used in our experiments. Our study did not test for the maximum temperature at which $B$. antillogorgium could survive and grow. However, Prada et al. (2010) report that octocorals bleached in 2005 when the maximum water temperature was $29.81{ }^{\circ} \mathrm{C}$. The fact that B. antillogorgium survived and grew at this elevated temperature when other octocorals lose their symbionts (Prada et al. 2010) indicates thermal tolerance, at least at this temperature. It is possible that the rapid adaptation seen in previous studies might also occur in B. antillogorgium if these genotypes were grown at higher temperatures. Elevated temperatures in excess of $30{ }^{\circ} \mathrm{C}$ are becoming frequent during the summer months in the Florida Keys (Online Resource 1), and current work is exploring the limits of thermal tolerance in B. antillogorgium to temperatures greater than $30^{\circ} \mathrm{C}$.

\section{In hospite polyp experiments}

There were no significant differences in the percent of visually infected polyps between genotypes and temperature treatments through Day 52. In general, the percent of infected polyps on Day 52 was largely congruent with the average number of symbiont cells per polyp at the end of the experiment; those genotypes that had a greater proportion of visibly infected polyps also had a greater average number of symbiont cells per polyp (Fig. 3b, c). Final symbiont cell density varied with genotype and temperature, indicating that symbionts were either taken up or grew at different rates within hosts. The lack of a consistent effect of temperature on symbiont density within polyps suggests that the establishment of the symbiosis at $30^{\circ} \mathrm{C}$ may be as stable as those at ambient temperatures $\left(26^{\circ} \mathrm{C}\right)$. Given the significant interaction between treatment temperature and symbiont genotype on symbiont density within polyps at the end of the experiment (Day 69), the ability of the symbiont to infect and thrive in the host likely depends on multiple factors, with potential for variation in the establishment and maintenance of the symbiosis (Davy et al. 2012; Hawkins et al. 2016). It is clear that biotic interactions (e.g., recognition and phagocytosis of algal symbionts, Davy et al. 2012) drive the establishment, while abiotic factors, such as temperature, may dictate the maintenance of the symbiosis (e.g., Rädecker et al. 2021).

Those symbiont genotypes that had the highest growth rates in vitro did not necessarily confer the highest survivorship under the same conditions in hospite, although thermal tolerance was observed. All treatments had relatively high polyp survival early in the experiment, with a more rapid decline in survivorship toward the end (Fig. 4). Many polyps survived extended heat exposure, with some surviving polyps in all treatments at $56 \mathrm{~d}$ post-inoculation. Furthermore, after $69 \mathrm{~d}$, all treatments except $\mathrm{G} 4$ at $30{ }^{\circ} \mathrm{C}$ had surviving polyps. This is a substantially longer exposure to heat stress than has been previously reported for in hospite experiments (i.e., Chakravarti et al. 2017: $28 \mathrm{~d}$; Buerger et al. 2020: 7 d). Our results suggest that the observed thermal tolerance exhibited by our symbiont types may have contributed to or enhanced the thermal tolerance of the holobiont, although the long-term value of this has yet to be determined.

In this study, the host-symbiont pairs exhibited thermal tolerance to temperatures above the seasonal maximum. At the elevated temperature, however, hosts infected with Breviolum cultures that had been reared at $30{ }^{\circ} \mathrm{C}$ did not consistently outperform their counterparts (i.e., hosts infected with cultures reared at $26^{\circ} \mathrm{C}$ ). This indicates that selection for thermal tolerance of certain genotypes likely occurred prior to the isolation of these symbionts. Increasingly elevated temperatures are becoming more commonplace on coral reefs (Heron et al. 2016; van Hooidonk et al. 2016; Hughes et al. 2018; Oliver et al. 2018), and repeated exposure to these elevated temperatures may have selected for symbiont genotypes capable of surviving our experimental temperature. Ultimately, our results indicate that there exists standing genetic variation within symbiont populations, which, in this case, contained genotypes that were thermally tolerant. These symbionts may be vital for the holobiont's survival, although the basis for this thermal tolerance requires further investigation.

\section{Role of the symbiont and implications for Caribbean reefs}

Most previous studies of the capacity for rapid thermal adaptation in symbionts have focused on Pacific strains of Symbiodiniaceae. Our results shed new light on the existence of thermally tolerant Caribbean coral endosymbionts 
in genera in addition to those thermally tolerant species in the genus Durusdinium (LaJeunesse et al. 2014). We provide key evidence that even in the absence of rapid adaptation to elevated temperatures, thermal tolerance may be widespread in some Breviolum species. It is likely that broad thermal tolerance is an inherent trait among these genotypes and perhaps among other species within Breviolum, particularly those within the B1 (ITS2-type) lineage (Pleistocene (B1) radiation, sensu LaJeunesse 2005; Parkinson et al. 2015) such as B. antillogorgium. For example, bleaching is rarely observed in Caribbean octocorals, but in the few reports of octocoral bleaching, Antillogorgia spp., (previously classified as Pseudopterogorgia), which harbor $B$. antillogorgium, were not observed to bleach (Lasker et al. 1984; Prada et al. 2010). Additionally, under induced bleaching and/or thermal stress, the octocoral Briareum asbestinum lost its dominant Breviolum ITS2 type B19 symbiont, which was replaced by a Breviolum ITS2 type B1 species (Lewis and Coffroth 2004; Poland and Coffroth 2019). Transitioning from a dominant symbiont species with lower thermal tolerance to a more thermally tolerant cryptic species during bleaching events may buffer Caribbean octocorals from increasing temperatures.

Coral reefs are in decline worldwide and some regions, such as the Caribbean, are experiencing a phase shift from scleractinian-dominated to octocoral-dominated ecosystems (Ruzicka et al. 2013; Lenz et al. 2015; Lasker et al. 2020). This pattern has been attributed, in part, to high levels of octocoral recruitment (Lasker et al. 2020). However, bleaching in octocorals is rarely observed during mass bleaching events (Lasker et al. 1984; Lasker 2003; Prada et al. 2010) and if it is observed, most species show a high level of resilience (Prada et al. 2010). The fact that species within Breviolum are the dominant symbionts in Caribbean octocorals (LaJeunesse 2002; van Oppen et al. 2005; Goulet et al. 2008), and that some symbiont species within this genus appear to have some level of thermal tolerance, as shown here, may contribute to this resilience. Additional studies are needed to determine the prevalence of these thermally tolerant symbionts, which may exist at background level, and their role in mitigating the effects of increasing temperatures on reef cnidarians. The survival of Caribbean reefs may be reliant on evolutionary rescue (Gomulkiewicz and Holt 1995) perpetrated by selection for these more thermally tolerant symbiont genotypes within a given species; a process that could be particularly important for specialist hosts that are not able to harbor different species of symbionts.

Acknowledgements We would like to thank H. Franklin, undergraduate volunteers, staff of the KML, the FKNMS and the FWC (Permit FKNMS-2014-018-A2 and SAL-18-2052-SR, respectively).
This work was supported by NSF-OCE-1559286 (MAC) and NSFOCE-1559105 (CPt), a UB Honors Research \& Creativity Grant (JAP) and a UB CURCA Award (KME). We are grateful to D. Williams, K.H. Kilbourne and J. Schijf for providing temperature data and to H. Lasker, A. Martinez, C. Wells, and two anonymous reviewers for helpful and insightful comments on previous drafts of this manuscript.

\section{Declarations}

Conflict of interest On behalf of all authors, the corresponding author states that there is no conflict of interest.

Open Access This article is licensed under a Creative Commons Attribution 4.0 International License, which permits use, sharing, adaptation, distribution and reproduction in any medium or format, as long as you give appropriate credit to the original author(s) and the source, provide a link to the Creative Commons licence, and indicate if changes were made. The images or other third party material in this article are included in the article's Creative Commons licence, unless indicated otherwise in a credit line to the material. If material is not included in the article's Creative Commons licence and your intended use is not permitted by statutory regulation or exceeds the permitted use, you will need to obtain permission directly from the copyright holder. To view a copy of this licence, visit http://creativecommons. org/licenses/by/4.0/.

\section{References}

Andras JP, Kirk NL, Coffroth MA, Harvell CD (2009) Isolation and characterization of microsatellite loci in Symbiodinium B1/B184, the dinoflagellate symbiont of the Caribbean sea fan coral, Gorgonia ventalina. Mol Ecol Resour 9:989-993

Baker AC (2003) Flexibility and specificity in coral-algal symbiosis: diversity, ecology, and biogeography of Symbiodinium. Annu Rev Ecol Evol Syst 34:661-689

Baums IB, Devlin-Durante MK, LaJeunesse TC (2014) New insights into the dynamics between reef corals and their associated dinoflagellate endosymbionts from population genetic studies. Mol Ecol 23:4203-4215

Bayliss SLJ, Scott ZR, Coffroth MA, terHorst CP (2019) Genetic variation in Breviolum antillogorgium, a coral reef symbiont, in response to temperature and nutrients. Ecol Evol 9:2803-2813

Berkelmans R, van Oppen MJH (2006) The role of zooxanthellae in the thermal tolerance of corals: a "nugget of hope" for coral reefs in an era of climate change. Proc Biol Sci 273:2305-2312

Buerger P, Alvarez-Roa C, Coppin CW, Pearce SL, Chakravarti LJ, Oakeshott JG, Edwards OR, van Oppen MJH (2020) Heatevolved microalgal symbionts increase coral bleaching tolerance. Sci Adv 6:eaba2498

Chakravarti LJ, van Oppen MJH (2018) Experimental evolution in coral photosymbionts as a tool to increase thermal tolerance. Front Mar Sci 5:227

Chakravarti LJ, Beltran VH, van Oppen MJH (2017) Rapid thermal adaptation in photosymbionts of reef-building corals. Glob Chang Biol 23:4675-4688

Chi J, Parrow MW, Dunthorn M (2014) Cryptic sex in Symbiodinium (Alveolata, Dinoflagellata) is supported by an inventory of meiotic genes. J Eukaryot Microbiol 61:322-327

Coffroth MA, Lasker HR, Diamond ME, Bruenn JA, Bermingham E (1992) DNA fingerprints of a gorgonian coral: a method for detecting clonal structure in a vegetative species. Mar Biol $114: 317-325$ 
Correa AMS, McDonald MD, Baker AC (2009) Development of clade-specific Symbiodinium primers for quantitative PCR (qPCR) and their application to detecting clade D symbionts in Caribbean corals. Mar Biol 156:2403-2411

Davy SK, Allemand D, Weis VM (2012) Cell biology of cnidariandinoflagellate symbiosis. Microbiol Mol Biol Rev 76:229-261

Díaz-Almeyda EM, Prada C, Ohdera AH, Moran H, Civitello DJ, Iglesias-Prieto R, Carlo TA, LaJeunesse TC, Medina M (2017) Intraspecific and interspecific variation in thermotolerance and photoacclimation in Symbiodinium dinoflagellates. Proc Biol Sci 284:20171767

Eakin CM, Lough JM, Heron SF (2009) Climate variability and change: monitoring data and evidence for increased coral bleaching stress. In: van Oppen MJH, Lough JM (eds) Coral Bleaching. Springer, Berlin Heidelberg, Berlin, Heidelberg, pp 41-67

Gomulkiewicz R, Holt RD (1995) When does evolution by natural selection prevent extinction? Evolution 49:201

Goulet TL (2006) Most corals may not change their symbionts. Mar Ecol Prog Ser 321:1-7

Goulet TL, Simmons C, Goulet D (2008) Worldwide biogeography of Symbiodinium in tropical octocorals. Mar Ecol Prog Ser 355:45-58

Grégoire V, Schmacka F, Coffroth MA, Karsten U (2017) Photophysiological and thermal tolerance of various genotypes of the coral endosymbiont Symbiodinium sp. (Dinophyceae). J Appl Phycol 29:1893-1905

Guillard RR, Ryther JH (1962) Studies of marine planktonic diatoms. I. Cyclotella nana Hustedt, and Detonula confervacea (Cleve) Gran. Can J Microbiol 8:229-239

Hawkins TD, Hagemeyer JCG, Warner ME (2016) Temperature moderates the infectiousness of two conspecific Symbiodinium strains isolated from the same host population. Environ Microbiol 18:5204-5217

Heron SF, Maynard JA, van Hooidonk R, Eakin CM (2016) Warming trends and bleaching stress of the world's coral reefs 1985-2012. Sci Rep 6:38402

Hoegh-Guldberg O (1999) Climate change, coral bleaching and the future of the world's coral reefs. Mar Freshwater Res 50:839

Hoegh-Guldberg O (2011) Coral reef ecosystems and anthropogenic climate change. Reg Environ Change 11:215-227

Hoegh-Guldberg O, Mumby PJ, Hooten AJ, Steneck RS, Greenfield P, Gomez E, Harvell CD, Sale PF, Edwards AJ, Caldeira K, Knowlton N, Eakin CM, Iglesias-Prieto R, Muthiga N, Bradbury RH, Dubi A, Hatziolos ME (2007) Coral reefs under rapid climate change and ocean acidification. Science 318:1737-1742

Hoegh-Guldberg O, Poloczanska ES, Skirving W, Dove S (2017) Coral reef ecosystems under climate change and ocean acidification. Front Mar Sci 4:158

Howells EJ, van Oppen MJH, Willis BL (2009) High genetic differentiation and cross-shelf patterns of genetic diversity among Great Barrier Reef populations of Symbiodinium. Coral Reefs 28:215-225

Howells EJ, Beltran VH, Larsen NW, Bay LK, Willis BL, van Oppen MJH (2011) Coral thermal tolerance shaped by local adaptation of photosymbionts. Nat Clim Chang 2:116-120

Hughes TP, Anderson KD, Connolly SR, Heron SF, Kerry JT, Lough JM, Baird AH, Baum JK, Berumen ML, Bridge TC, Claar DC, Eakin CM, Gilmour JP, Graham NAJ, Harrison H, Hobbs J-PA, Hoey AS, Hoogenboom M, Lowe RJ, McCulloch MT, Wilson SK (2018) Spatial and temporal patterns of mass bleaching of corals in the Anthropocene. Science 359:80-83

Jones AM, Berkelmans R, van Oppen MJH, Mieog JC, Sinclair W (2008) A community change in the algal endosymbionts of a scleractinian coral following a natural bleaching event: field evidence of acclimatization. Proc Biol Sci 275:1359-1365
Kahng SE, Benayahu Y, Lasker HR (2011) Sexual reproduction in octocorals. Mar Ecol Prog Ser 443:265-283

Karim W, Nakaema S, Hidaka M (2015) Temperature effects on the growth rates and photosynthetic activities of Symbiodinium cells. J Mar Sci Eng 3:368-381

Keshavmurthy S, Hsu C-M, Kuo C-Y, Meng P-J, Wang J-T, Chen CA (2012) Symbiont communities and host genetic structure of the brain coral Platygyra verweyi, at the outlet of a nuclear power plant and adjacent areas. Mol Ecol 21:4393-4407

Kirk NL, Andras JP, Harvell CD, Santos SR, Coffroth MA (2009) Population structure of Symbiodinium sp. associated with the common sea fan, Gorgonia ventalina, in the Florida Keys across distance, depth, and time. Mar Biol 156:1609-1623

LaJeunesse T (2002) Diversity and community structure of symbiotic dinoflagellates from Caribbean coral reefs. Mar Biol 141:387-400

LaJeunesse TC (2005) "Species" radiations of symbiotic dinoflagellates in the Atlantic and Indo-Pacific since the Miocene-Pliocene transition. Mol Biol Evol 22:570-581

LaJeunesse T (2020) Zooxanthellae. Curr Biol 30:R1110-R1113

LaJeunesse TC, Smith RT, Finney J, Oxenford H (2009) Outbreak and persistence of opportunistic symbiotic dinoflagellates during the 2005 Caribbean mass coral "bleaching" event. Proc Biol Sci 276:4139-4148

LaJeunesse TC, Parkinson JE, Reimer JD (2012) A genetics-based description of Symbiodinium minutum sp. nov. and S. psygmophilum sp. nov. (Dinophyceae), two dinoflagellates symbiotic with cnidaria. J Phycol 48:1380-1391

LaJeunesse TC, Wham DC, Pettay DT, Parkinson JE, Keshavmurthy S, Chen CA (2014) Ecologically differentiated stress-tolerant endosymbionts in the dinoflagellate genusSymbiodinium (Dinophyceae) Clade D are different species. Phycologia 53:305-319

Lasker HR (2003) Zooxanthella densities within a Caribbean octocoral during bleaching and non-bleaching years. Coral Reefs 22:23-26

Lasker HR, Peters EC, Coffroth MA (1984) Bleaching of reef coelenterates in the San Blas Islands, Panama. Coral Reefs 3:183-190

Lasker HR, Martínez-Quintana Á, Bramanti L, Edmunds PJ (2020) Resilience of octocoral forests to catastrophic storms. Sci Rep 10:4286

Lenz EA, Bramanti L, Lasker HR, Edmunds PJ (2015) Long-term variation of octocoral populations in St. John. US Virgin Islands Coral Reefs 34:1099-1109

Lewis CL, Coffroth MA (2004) The acquisition of exogenous algal symbionts by an octocoral after bleaching. Science 304:1490-1492

Mieog JC, van Oppen MJH, Cantin NE, Stam WT, Olsen JL (2007) Real-time PCR reveals a high incidence of Symbiodinium clade $\mathrm{D}$ at low levels in four scleractinian corals across the Great Barrier Reef: implications for symbiont shuffling. Coral Reefs 26:449-457

Muscatine L, Cernichiari E (1969) Assimilation of photosynthetic products of zooxanthellae by a reef coral. Biol Bull 137:506-523

Muscatine L, Porter JW (1977) Reef corals: mutualistic symbioses adapted to nutrient-poor environments. Bioscience 27:454-460

Oliver JK, Berkelmans R, Eakin CM (2018) Coral bleaching in space and time. In: Lough $\mathrm{J}$, van Oppen $\mathrm{M}$ (eds) Coral bleaching: patterns, processes, causes and consequences. Springer Ecological Series. Cham, Switzerland, pp 27-49

Parkinson JE, Baums IB (2014) The extended phenotypes of marine symbioses: ecological and evolutionary consequences of intraspecific genetic diversity in coral-algal associations. Front Microbiol 5:445

Parkinson JE, Coffroth MA, LaJeunesse TC (2015) New species of Clade B Symbiodinium (Dinophyceae) from the greater 
Caribbean belong to different functional guilds: S. aenigmaticum sp. nov., S. antillogorgium sp. nov., S. endomadracis sp. nov., and S. pseudominutum sp. nov. J Phycol 51:850-858

Pettay DT, LaJeunesse TC (2007) Microsatellites from clade B Symbiodinium spp. specialized for Caribbean corals in the genus Madracis. Mol Ecol Notes 7:1271-1274

Petzoldt T (2019) growthrates. URL: https://github.com/tpetzoldt/ growthrates

Poland DM, Coffroth MA (2019) Host growth and survivorship varies with endosymbiotic algal partner in developing cnidarians. Mar Ecol Prog Ser 612:87-100

Prada C, Weil E, Yoshioka PM (2010) Octocoral bleaching during unusual thermal stress. Coral Reefs 29:41-45

Quigley KM, Baker AC, Coffroth MA, Willis BL, van Oppen MJH (2018) Bleaching resistance and the role of algal endosymbionts. Ch. 6 pp. 111-151. In: Coral Bleaching: Patterns, processes, causes and consequences eds; J. Lough and M. van Oppen. Springer Ecological Series. Cham, Switzerland

R Core Team (2020). R: A language and environment for statistical computing. R Foundation for Statistical Computing, Vienna, Austria. URL: https://www.R-project.org/

Rädecker N, Pogoreutz C, Gegner HM, Cárdenas A, Roth F, Bougoure J, Guagliardo P, Wild C, Pernice M, Raina J-B, Meibom A, Voolstra CR (2021) Heat stress destabilizes symbiotic nutrient cycling in corals. Proc Natl Acad Sci USA 118(5):e2022653118

Ruzicka RR, Colella MA, Porter JW, Morrison JM, Kidney JA, Brinkhuis V, Lunz KS, Macaulay KA, Bartlett LA, Meyers MK, Colee J (2013) Temporal changes in benthic assemblages on Florida Keys reefs 11 years after the 1997/1998 El Niño. Mar Ecol Prog Ser 489:125-141

Santos SR, Taylor DJ, Coffroth MA (2001) Genetic comparisons of freshly isolated versus cultured symbiotic dinoflagellates: implications for extrapolating to the intact symbiosis. J Phycol 37:900-912

Santos SR, Gutiérrez-Rodríguez C, Lasker HR, Coffroth MA (2003) Symbiodinium sp. associations in the gorgonian Pseudopterogorgia elisabethae in the Bahamas: high levels of genetic variability and population structure in symbiotic dinoflagellates. Mar Biol 143:111-120

Santos SR, Shearer TL, Hannes AR, Coffroth MA (2004) Fine-scale diversity and specificity in the most prevalent lineage of symbiotic dinoflagellates (Symbiodinium, Dinophyceae) of the Caribbean. Mol Ecol 13:459-469
Silverstein RN, Correa AMS, Baker AC (2012) Specificity is rarely absolute in coral-algal symbiosis: implications for coral response to climate change. Proc Biol Sci 279:2609-2618

Silverstein RN, Cunning R, Baker AC (2015) Change in algal symbiont communities after bleaching, not prior heat exposure, increases heat tolerance of reef corals. Glob Chang Biol 21:236-249

Thornhill DJ, Howells EJ, Wham DC, Steury TD, Santos SR (2017) Population genetics of reef coral endosymbionts (Symbiodinium, Dinophyceae). Mol Ecol 26:2640-2659

Torda G, Donelson JM, Aranda M, Barshis DJ, Bay L, Berumen ML, Bourne DG, Cantin N, Foret S, Matz M, Miller DJ, Moya A, Putnam HM, Ravasi T, van Oppen MJH, Thurber RV, VidalDupiol J, Voolstra CR, Watson S-A, Whitelaw E, Munday PL (2017) Rapid adaptive responses to climate change in corals. Nat Clim Chang 7:627-636

Tukey JW (1949) Comparing individual means in the analysis of variance. Biometrics 5:99-114

van Hooidonk R, Maynard J, Tamelander J, Gove J, Ahmadia G, Raymundo L, Williams G, Heron SF, Planes S (2016) Localscale projections of coral reef futures and implications of the Paris Agreement. Sci Rep 6:39666

van Oppen MJH, Mieog JC, Sánchez CA, Fabricius KE (2005) Diversity of algal endosymbionts (zooxanthellae) in octocorals: the roles of geography and host relationships. Mol Ecol 14:2403-2417

van Oppen MJH, Souter P, Howells EJ, Heyward A, Berkelmans R (2011) Novel genetic diversity through somatic mutations: fuel for adaptation of reef corals? Diversity (basel) 3:405-423

Wilkinson SP, Fisher PL, van Oppen MJH, Davy SK (2015) Intragenomic variation in symbiotic dinoflagellates: recent divergence or recombination between lineages? BMC Evol Biol $15: 325$

Williams DE, Miller MW (2015) Water temperature data from reef sites off the upper Florida Keys from 2003-09-18 to 2019-11-25 (NCEI Accession 0126994). [Water temperature data from reef sites off the upper Florida Keys from 2003-09-18 to 2019-11-25 (NCEI Accession 0126994)]. NOAA National Centers for Environmental Information. Dataset. https://www.ncei.noaa. gov/archive/accession/0126994. Accessed [7 Jan 2021.]

Publisher's Note Springer Nature remains neutral with regard to jurisdictional claims in published maps and institutional affiliations. 